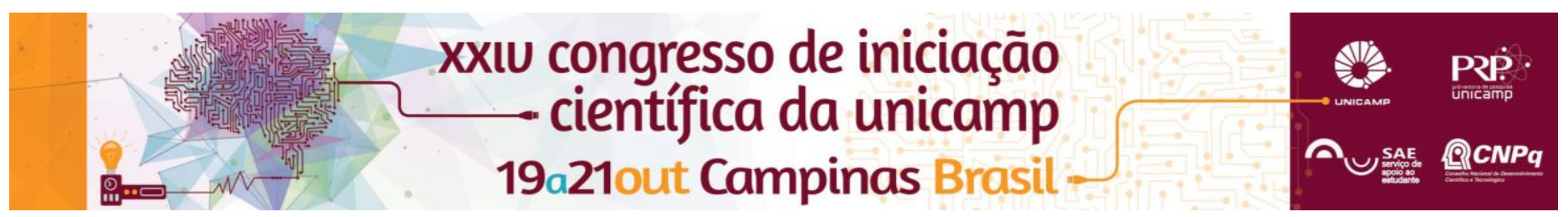

\title{
Dificuldades apontadas na implantação/adequação dos requisitos da nova ISO 9001:2015 por empresas de produção seriada e empresas de serviços
}

\author{
João Vitor Maia Correia Motta*, Rosley Anholon.
}

\section{Resumo}

A implantação bem-sucedida de uma norma da qualidade é um feito fundamental no contexto competitivo empresarial atual. Por mais que, todo ano, diversas empresas obtenham esses certificados, é notório que há uma série de dificuldades a serem superadas no processo de certificação e que fatores como o setor de atuação da empresa interferem nesse processo. Tendo isso em vista, o objetivo deste projeto de iniciação científica é investigar e entender essas dificuldades para empresas de serviços e empresas de produção seriada. Adicionalmente, também se faz um estudo específico acerca da nova versão da norma ISO 9001:2015.

\section{Palavras-chave}

Engenharia de Produção, Sistemas de Gestão da Qualidade, ISO 9001.

\section{Introdução}

No ambiente econômico recente, cada vez mais empresas implantam Sistemas de Gestão da Qualidade (SGQ) como tentativa de trazer vantagens competitivas suplementares para seus negócios. A implantação de um SGQ pode tanto ser usada para garantir os requisitos mínimos de qualidade exigidos quanto para promover ganho de eficiência e benefícios operacionais reais. $O$ processo de certificação em normas de qualidade envolve uma série de dificuldades. O objetivo deste projeto é analisar as principais dificuldades observadas na implantação ou transição de normas de qualidade bem como os possíveis pontos problemáticos na implantação da nova versão da norma ISO 9001:2015. Esta análise foi realizada para dois diferentes tipos de empresas (serviços e produção seriada).

\section{Resultados e Discussão}

O início do projeto baseou-se em uma ampla revisão bibliográfica, além do estudo da nova ISO 9001:2015, que serviram de base para a elaboração de um questionário contendo 24 perguntas relacionadas às dificuldades na implantação/transição de normas de qualidade e 45 perguntas associadas às possíveis dificuldades na implantação da nova norma. Este questionário foi aprovado pelo Comitê de Ética em Pesquisas da Unicamp e enviado para profissionais atuantes na área de qualidade. Os respondentes outliers foram identificados e eliminados por meio de mapas espaciais decorrentes do uso da ferramenta Escalonamento Multidimensional (EMD). Foram consideradas válidas para a análise 22 questionários relativos aos profissionais do segmento de serviços e 20 relativos aos profissionais do segmento de produção seriada. Tanto as dificuldades na implantação de normas de qualidade com as possíveis dificuldades na implantação da nova norma ISO 9001:2015 foram ordenadas valendo-se da Análise Fatorial Exploratória (AFE) para um único fator, segundo os scores gerados. Os resultados aqui apresentados correspondem apenas a uma pequena parte total obtido com a pesquisa:

\section{a) Dificuldades na transição de normas}

Foi possível identificar a repetição de seis fatores de maior destaque nos dois segmentos estudados:

F1: compreensão deficitária de como o SGQ pode melhorar as atividades cotidianas da empresa

F2: dificuldade em alinhar a cultura organizacional da empresa com os princípios difundidos pela norma

F3: dificuldade em entender que a motivação para a certificação deve ocorrer em função da melhoria dos processos e não da pressão de alguns clientes

F4: falta de treinamentos ministrados por especialistas focando pontos específicos da norma mais complexos

F5: dificuldade na padronização dos processos analisados para atender aos requisites

F6: falta de integração de todos os departamentos da empresa visando ganhos sinérgicos.

a) Possíveis dificuldades na implantação da nova ISO Foi possível identificar a repetição de quatro fatores de maior destaque nos dois segmentos estudados:

F1: definir as mudanças e tendências que podem impactar os objetivos da organização;

F2: definir as relações com as partes interessadas, suas percepções e valores;

F3: definir a disponibilidade de recursos e suas prioridades e mudança tecnológica;

F4: suporte a outros setores da gestão para demonstrar sua liderança como aplicada às suas áreas de responsabilidade;

\section{Conclusões}

Foram identificadas dificuldades similares nos dois setores analisados, principalmente em relação à cultura organizacional e ao planejamento da qualidade, porém o setor de serviços demonstra uma dificuldade maior na relação com seus colaboradores, enquanto o de produção seriada demonstra maior dificuldade com a gestão de recursos.

\section{Agradecimentos}

Agradeço ao Prof. Dr. Rosley Anholon pela orientação e agradeço especialmente ao PIBIC e ao CNPq. 